\title{
In-service teachers' challenges to implementing an approach to critical thinking and critical reading in Chile
}

\author{
Leonardo Veliz \\ School of Education, Excelsia College, 69-71 Waterloo Rd, Macquarie Park NSW 2113, Australia \\ leonardo.veliz@excelsia.edu.au
}

\section{ARTICLE INFO}

Article history

Received 22 February 2021

Revised 06 April 2021

Accepted 29 December 2021

Keywords

critical thinking in Chile

critical reading

EFL in Chile

teacher preparation

teaching critical thinking

\section{ABSTRACT}

The present study reports on the challenges of implementing an approach to critical thinking and critical reading in English language teaching (ELT) in Chile. Participants in this research are in-service teachers of English enrolled in a Master's course in Teaching English as a Foreign Language (TEFL) in Chile. In order to develop and construct a thorough understanding of the participants' past and present academic literacy experiences, they were invited for one-to-one meetings (semi-structured interviews) where, rather than reminiscing about past literacy experiences, they were encouraged to engage in narratives about their experiences with and challenges of developing a socially critical awareness of literacy at university, and in their current teaching practices. Analysis of the participants' accounts revealed, first and foremost, the pervasive presence of literacy practices that reflect and favor a strong culture of compliance over critical reflection, and, secondly, great concerns about the lack of systematic preparation in English teacher education (ETE) programs to develop and implement a more critical stance toward critical thinking and critical reading. The paper concludes by interrogating and challenging current university practices that, based on the participants' views, seem to replicate a culture that reproduces both social and cultural inequalities.

This is an open access article under the CC-BY-SA license.

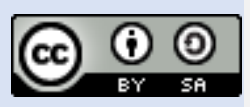

How to Cite: Veliz, L. (2021). In-service teachers' challenges to implementing an approach to critical thinking and critical reading in Chile. English Language Teaching Educational Journal, 4(3), 161-173.

\section{Introduction}

There is consensus among different stakeholders in education that critical thinking (CT) is an important asset in today's world. Lin and Luk (2015) point out that "critical thinking is believed to be an essential skill for 21 st century survival and has therefore been widely promoted in education" ( $p$. 67). Its significance in education and, in particular, to students' learning has been echoed by several researchers (e.g., Marzban \& Barati, 2016; Yousefi \& Mohammadi, 2016; Aghaei, Koo, Noor \& Rajabi, 2014) who argue that CT is a fundamental contributor to students' overall academic success.

Closely connected with the notion of CT is what is understood as 'critical reading' (CR). CR can be seen as a thread of critical language awareness (CLA), an area which, according to Wallace (2003) has been relatively neglected. The aim of CLA has been largely viewed as "raising students' awareness of how the uses of language in all its realizations serve to perpetuate dominant discourses and the ideologies they encode" (Wallace, 2003, p. 2). From the perspective of CR theory, engaging critically with texts entails becoming "more powerful users of language" (Manarin, Carey, Rathburn, \& Ryland, 2015 , p. 4), a process which, in practice, involves empowering readers to unpack 'the intricacies of 
meanings in texts' (Wallace, 2003; Shokouhi \& Latifi, 2019; Moghadam, Narafshan \& Tajadini, 2021), and to appropriate the affordances of reading critically for academic success.

In English language teaching (ELT) classrooms, critical reading can be exercised in multiple ways. Banegas and Villacañas de Castro (2016) argue that it can be developed and promoted through the analysis of different text types, or the identification of values, assumptions, proofs and fallacies in, for instance, news, photographs, advertisements or other modes of meaning making. Despite the viability of executing these pedagogical techniques in the development of critical reading, teachers' positive intentions and attempts to implement a critical approach to reading can be hampered by a range of organizational, educational and socio-political factors (Wallace, 2003; Toy \& Ok, 2012). In a world where education has become a commodity and an export (Dobinson, 2014), and particularly characterized by a strong managerial culture of compliance, the teaching of reading is often reduced to the production and reproduction of dominant discourses which, more often than not, respond to standards-based practices of teaching and learning to read in a foreign language (Brown et al., 2004). In order to respond to some of these issues, and therefore gain insights into the various factors that problematize effective pedagogies to the teaching of critical reading in Chile, the present work seeks to uncover in-service EFL teachers' understanding of CT in English language teacher education programs in Chile, and of the challenges encountered in their practices that facilitate or interfere with the implementation of an approach to CT and CR.

The present study seeks to unveil the perceptions, views and understanding of in-service EFL teachers regarding the role of CT in English teacher education programs in Chile as well as the challenges they face in implementing a critical pedagogy approach to the teaching of literacy skills. The research questions which we aim to address are as follows:

a. What is in-service teachers' understanding of the role of CT in English language teacher training programs in Chile?

b. What are the perceived challenges faced by in-service teachers in implementing and practicing critical pedagogy in their own teaching contexts?

\subsection{Teaching critical thinking and critical reading}

Despite the lack of consensus over ideas about whether CT should be viewed as a set of dispositions, higher-order thinking skills (Davies \& Barnett, 2015; Shahri, 2018), or a non-overt social practice (Atkinson, 1997), we embrace the view that rather than looking at different approaches to CT as incongruous with each other, they should be seen holistically as complementary. In practice, and for the purpose of our work, we do not wish to justify the exclusion or inclusion of a particular stance on CT; rather, we acknowledge and support the idea that CT is a skill and can therefore be taught and developed (see Wallace \& Jefferson, 2015), and that it is, what Benesch (1993) calls, 'a learning process for democracy', notion that relies heavily upon the principles of critical pedagogy.

Although the conceptual boundaries between CT and CR are not often well defined, these two concepts are seen as closely intertwined in our study whereby reading critically is understood as being embedded in a much broader domain which involves a set of skills, predispositions and attitudes to thinking critically (Benesch, 1993). Without drawing a distinction between CT and CR, Benesch (1993) points out that "critical thinking (or critical reading) is often listed as one or more of a number of hierarchically ordered cognitive skills" (p. 546). A far less cognitive-dominant view of CT is put forth by Wallace (2015) who states that "criticality cannot be linked to innate linguistic competence but is socially and educationally learned" (p. 4), notion that tacitly touches on the uniqueness and distinctiveness of CT approaches across cultures. Apart from the implied learnable and teachable capacity of CT, this definition touches on the social situatedness dimension of the concept, which is generally associated with the principles of critical pedagogy. Along the lines of critical pedagogy, a similar view is expressed by Atkinson (1997) who argues that:

Rather than being a well-explicated and educationally usable concept, critical thinking may more in the nature of social practice; that is, what we commonly refer to as critical thinking may be an organic part of the very culture that holds it up as an admirable achievement -more at the level of common sense than rational, transparent, and -especially -teachable set of behaviors. (p. 72) 
The emphasis on the nature of CT as a social practice is neatly interwoven with Wallace's (2015, p. 3) definition of CR who views it as one strand within the wider area of critical language awareness. From this perspective, reading critically is understood in relation to understanding the social, political and ideological aspects of a text. Indeed, this has been a pressing concern in the fields of language and literacy education which is, in particular, critical literacy (Lau, 2013; Janks, 2014; Rogers, 2014; Romero \& Bobkina, 2021) state," (p. 528). This becomes central in ELT in order to develop and promote post-modern pedagogies (Ahmadi \& Maftoon, 2015) to encourage various forms of criticality (Banegas \& Villacañas de Castro, 2016) so that students have sufficient opportunities to engage actively in the construction of text meaning.

The development of 'criticality', and particularly how university can best fosters CT and CR skills (Huber \& Kuncel, 2016), has given rise to different questions as to whether, for example, an intensive reading course can help in the cultivation of CT skills (Tang, 2016), and ultimately over how to mitigate the effects of 'banking education', and maximize the potential power of 'transformative education'. The pedagogical implementation of an approach to reading and thinking critically is considered by some a daunting task (e.g., Crookes \& Lehner, 1998). This is probably due to the lack of systematic instruction of critical reading and CT skills (Huber \& Kuncel, 2016; Welch, Hieb, \& Graham, 2015). In cases where there is a pedagogical attempt to approach students' reading and thought processes from a critical perspective (e.g. Smith, Rama, \& Helms, 2018; Welch et al., 2015), success is, in our view, often hampered by numerous constraints imposed by the demands of a corporate educational culture driven by strong managerial control (Brown et al., 2004), local and global politics of accountability (Lewis \& Young, 2013), and the pervasive pressures of high stakes testing (Klenowski \& Wyatt-Smith, 2012). This is supported by Orlowski (2011) who argues that "the emphasis on liberal arts and critical thinking has been replaced by the human capital paradigm in which the focus is on filling the requirements of capital" (p. v). This by no means points to the impossibility of engaging students in tasks, activities and learning processes that involve a level of criticality; rather, it raises awareness of some of the challenges that may need to be overcome by teachers in order to implement classroom practice that promotes and fosters CT and CR.

\subsection{Description of the Study and its Social Context}

To understand the educational and sociopolitical context that drives the present study, there must be some reference to the various significant effects of the military government (1973-1990) on education as well as the neoliberal and neoconservative ideologies that have shaped the current Chilean system of education.

The military take-over in 1973 brought about a series of radical social, political, economic and educational changes in the Chilean society. Based on the premise "absolute control of the nation" (Beltrán \& Preller, 2003, p. 11), Chile witnessed military intervention in almost every human activity. In education, for example, several drastic measures were taken to extirpate 'the Marxist cancer'; that is, any views and ideologies that were perceived as posing a threat to the prevailing order. One of these measures was the development of a policy of control with the intent to eradicate all existing teachers' unions (Nuñez, 1984). The suppression of teacher associations was vital for the government as these were seen as instances of political campaign and of voices of dissent.

In an attempt to prevent what the government labeled 'Marxist ideologies' from permeating higher education institutions, a series of episodes of book burning and obliteration of libraries took place throughout the country (Beltrán \& Preller, 2003). This strong action was primarily intended to avert a rise of 'critical thinkers' and to prescribe what the military government considered 'core knowledge', characterized by a culture of conformity and passive absorption of carefully selected knowledge. This practice, which, to a greater extent, still prevails in the present day in the Chilean society, was aimed at discouraging teachers and students to think critically about society and, most importantly, about the sociopolitical issues that had unfolded.

During the military government, especially around the 1980s, Chile was one of the first countries in Latin America to embrace neoliberal models of education. In 2009, the 'Internacional de Educación para América Latina' (International of Education for Latin America) concluded that Chile was an emblematic case in its rapid and early adherence to neoliberal policies under the dictatorship period (Inzunza, Assaél, \& Scherping, 2011, p. 268; Goodman \& Cocca, 2014). As a result, Chile served as a model for Latin America and marked a clear tendency towards the adoption of such policies. Apart from the implementation of a series of free-market reforms best described as a neoliberal revolution, 
Chile's endorsement of a neoliberal model in education under the dominance of a military government impacted quite significantly the practices and pedagogies of education at all levels.

In Mora's $(2013,2014)$ view, one of the aims of Pinochet government was to minimize, and ideally neutralize, all possible educational instances and opportunities that could ignite commitment, social responsibility and bravery in young people to realize that they had the power to critique and challenge the status quo. This is, in our view, one of the main negative forces, and probably causes, of the current ELT climate in Chile characterized by an increasing neglect of criticality in ETE programs, and more specifically in the teaching and learning of academic literacy (reading and writing). This is to a great extent supported by Bellei \& Muñoz (2021) who comment that the unsatisfactory status of our current education system has its roots in the changes introduced by the military government.

\section{Method}

\subsection{Research Design}

The research questions in the present study are aimed generally at exploring and comprehending in-service teachers' perceptions and understandings of some of the challenges they face in practicing, exercising and implementing critical pedagogy in their teaching contexts. The research questions in this study is qualitative. This in turn entails that the methods for data collection, data analysis and overall methodological procedures underpinning the study have been informed by an interpretive paradigm characterized by a concern for the individual (Creswell \& Poth, 2016). This suggests that our work is not pursuing to find definitive answers to specific questions or phenomena; rather, it attempts to explore and comprehend them as they occur in specific contexts under certain circumstances.

\subsection{Participants}

Eight in-service Chilean teachers of English as a foreign language (EFL) participated in the study. All the participants had been teaching EFL in different educational contexts (primary, secondary and higher education) for at least three years. These in-service teachers were all enrolled in a Masters of TEFL program in Chile by the time the research was conducted. The group of participants is comprised of three female teachers and five males, all aged between 28-33. For reasons of confidentiality, their names were kept in anonymity and pseudonyms were used instead. In order to have a more holistic understanding of the participants' profile, some demographic data were also collected during the interview which, in future research, may be used to explore, for instance, the participants' past literacy practices in primary and secondary school, the role of CT in school, and any potential relationship between participants' educational, and socio-economic background and their understanding and use of CT in current teaching practices. Table 1 shows a summary of some of the demographic data obtained from participants.

Table 1. Participants' demographic information

\begin{tabular}{llccc}
\hline \multicolumn{1}{c}{$\begin{array}{c}\text { Participant } \\
\text { number }\end{array}$} & Type of school & $\begin{array}{c}\text { Years of teaching } \\
\text { experience }\end{array}$ & Gender & Age \\
\hline $\begin{array}{l}\text { Participant } 1 \\
\text { (Paula) }\end{array}$ & Private & 3 & Female & 29 \\
$\begin{array}{l}\text { Participant } 2 \\
\text { (Sandra) }\end{array}$ & Private (Catholic) & 2.5 & Female & 30 \\
$\begin{array}{l}\text { Participant } 3 \\
\text { (Andrea) }\end{array}$ & Government & 4.5 & Female & 33 \\
$\begin{array}{l}\text { Participant } 4 \\
\text { (Fernando) }\end{array}$ & Private (Catholic) & 2 & Male & 28 \\
$\begin{array}{l}\text { Participant } 5 \\
\text { (David) }\end{array}$ & Government & 1.5 & Male & 31 \\
\hline
\end{tabular}

The recruitment process was by email. An email was sent to first- and second-year students inviting them to participate in the study. The email briefly explained the purpose of the study and provided contact information of one of the researchers to respond to in case they had an interest in taking part in the research. 11 responses were received over a period of three weeks. Throughout the process of 
contacting participants individually to hand over consent forms and arrange a convenient day and time for interview, three withdrew from the study, bringing the number down to eight. Due to the depth of data gathered in the interviews, however, five out of the eight participants were randomly selected for the purpose of this study.

\subsection{Data Collection and analysis}

The method utilized to gather data for the present study consisted of a semi-structured interview with each of the participants. The interview, which went for about 20-30 minutes, was conducted in English as all in-service teachers were proficient users of English. Due to the reflective nature of the interviews where participants were encouraged to tell us about their past experiences, what (Junejo, Sarwar \& Ahmed, 2017) call 'the big stories', that is, their life and academic histories, the interviews are referred to as 'one-to-one meetings' in an attempt to downplay the semi-structured nature of the encounters. The meetings with the participants were in fact motivated by three prompt questions which generally framed each of the research questions in the study. As the conversations unfolded, further related questions were asked to explore issues arising during conversation. All individual meetings with participants were audio-taped and transcribed. The prompt questions asked included: (1) What do you understand by critical thinking and critical reading, and what is their significance to English teacher education programs? (2) Could you please tell us about your early literacy practices and experiences, including home, school and university? ;(3) Could you tell us if you have had any limitations or challenges in implementing a critical thinking and critical reading approach in your teaching contexts?

Inductive, thematic analysis was used to identify, analyze and report patterns (themes) within the data that were linked to the research questions. With inductive analysis, emerging themes are closely connected to the data itself rather than being theoretically driven. The data analysis procedures involved different rigorous steps. Firstly, the transcribed data were read several times to familiarize ourselves with the nature of responses, and from there start developing a sense of what themes could emerge from it. Secondly, ideas and key words that systematically cropped up in the responses were color-coded in order to begin looking for possible patterns across the data. Next, the color-coded ideas and key words were collated into potential themes. These were then checked and reviewed in relation to their relevance to the research questions around which responses had been provided. Finally, once the themes had been identified and checked against how well they informed the research questions, they were labeled. This rigorous process was followed by a member-checking procedure to enhance the validity and transferability of the findings.

Three themes were identified in the analysis of the data; two themes emerged for research question 1 , and one theme for question 2 . Table 2 shows the emerging themes relating to each research question.

Table 2. Emerging themes from the research questions

\begin{tabular}{cl}
\hline Research questions & \multicolumn{1}{c}{ Themes } \\
\hline Research question 1 & Critical thinking as an asset to teachers' professional \\
& practice \\
& Critical thinking and critical reading not imagined, but \\
& existent in different forms \\
Research question 2 & Feeling pressured for assessment
\end{tabular}

It is important to note that although all interview data from participants were rich and insightful, the identified themes emerged mainly from responses pertaining to five participants. Since qualitative data may become unwieldy at times (Barkhuizen, 2016), both in terms of depth and breadth, a sample of five out of eight is used in this work. The responses, however, are representative exemplars of thematic patterns found across all participants.

\section{Findings and Discussion}

The findings are reported in the order of the research questions outlined above along with the themes pertaining to each of them. In order to address the first research question, the first two emerging 
themes are discussed first, while the second research question is addressed later in the discussion of the third theme.

$R Q$ 1: What is in-service teachers' understanding of the role of $C T$ in English language teacher training programs in Chile?

\subsection{Critical thinking as an asset to teachers' professional practice}

Overall, in-service teachers' responses show a relatively good understanding of the role of CT in education, and in life-long learning. Specifically, some participants stressed the value and centrality of CT skills for life. This was evident in Sandra's comments:

\section{Now that I am a teacher myself, I think that critical thinking is something, like a very important skill that should be developed in all subjects because students will need it in their lives.}

Understood as a 'very important skill', Sandra considers that CT should permeate all school subjects, a position which seems to imply that, as far as her own experience is concerned, CT as a teachable and learnable set of skills has not pervaded her experiences as a teacher or learner. Another in-service teacher, Paula, who also holds the opinion that CT is a skill for life, stresses the value of $\mathrm{CT}$ in higher education and, in particular, in teacher education programs:

Well, critical thinking skills are always important for whatever we do in life. I really think there should be like constant reference to these skills, and how to use these skills when we read and write academic works

An interesting thing that stands out in Paula's observation is her appreciation of CT as 'skills', which partly aligns with Sandra's comment. She also stresses one significant point about the importance of CT in the whole life, and not merely in education. Moore (2011) affirms that defining CT has never been simple or unproblematic where, for some, it is seen as a universal, abstract category, while others view it as analytical thinking and critical reasoning. Where some clear consensus is found, however, researchers have agreed that "CT is vital to success in tertiary level courses" (Floyd, 2011, p. 289). This is further supported by Davis (2011) who states that universities have generally made a point of emphasizing the significance of $\mathrm{CT}$ as a "a generic skill that is central to most, if not all, subjects" (p. 255). Paula, in particular, feels very strongly about the need to systematically use and incorporate CT skills in academic reading and writing in English teacher education programs.

Within more knowledge, discipline-specific realms, Fernando seems to be of the idea that all forms of knowledge should be channeled through a process of thinking critically, which, in the end, all contribute to teachers' professional practice.
Not just in teacher training but in all programs and courses critical thinking should be the heart of anything teachers and students do, because this process of thinking deeper will kind of filter any kind of knowledge that is assimilated to decide what is truthful or worth to learn for the future, and this allows teachers to make learning more engaging and interesting.

Fernando's view of CT aligns well with Barnett's (2011) reconceptualization of CT which brings thinking skills and social action together into the notion of 'critical being'. This broader term refers to an integration of three forms of criticality: critical reasoning, critical self-reflection and critical action. Fernando's view of the central place that CT should have in teachers' and students' practices is indicative of how $\mathrm{CT}$, in his opinion, enables us to make more informed judgments and decisions about what to teach, how to teach it, and, therefore, how to exercise their profession, thus tapping into 'critical action', one of the three domains of criticality.

Closely connected with the notion of 'critical action', other in-service teachers also stressed on the affordances of CT to their pedagogies as "modes of improving teachers' and students' abilities to read and write" (Andrea). More specifically, Andrea adds that:

Critical thinking is a necessary ingredient in how we teach reading and writing to our second language learners; this means that not having this ingredient in our teachings doesn't allow us to think properly about the role and status of English in the world, and our students have to know about this, too. 
From this, it can be observed that CT is not only central to the teaching of reading and writing, and therefore to teachers' overall pedagogies, but also to a critical recognition of the position of English in the world. This "thinking properly", as Andrea calls it, may involve understanding of ELT and colonialism (Wass, Harland \& Mercer, 2011). A rather similar view is expressed by David who stresses the importance of CT to his own professional development as a way to better understand power inequalities in society.
It's always been important for me to develop as a teacher to know more and more about critical thinking because for me it's something that really opens our eyes to really see the differences in society. For example, in Chile it's really different if you speak English or not, so you if know the language, you have power, and critical thinking really helps you to see these things.

The value ascribed to CT as evident in this teacher's comment suggests that it seems to be an essential tool to better understand (power) differences in society driven by the affordances of the English language.

Overall, responses reveal quite clearly in-service teachers' critical stance on the role of CT in their teacher education programs, and, most importantly, in their own teaching/professional practices. Seeing reflection, and therefore CT, as an opportunity through which instances of inequalities, injustices, power differences and oppression may be uncovered, questioned and transformed is something that is of great significance to the respondents. Despite their recognition of the importance of CT in ETE programs, participants expressed great concerns about the actual absence of systematic approaches or pedagogies that promote critical reflection or CT in ETE courses.

\subsection{Critical thinking, not imagined but existent in different forms}

The second theme discussed is the existing forms of CT. A rather common view held by teachers concerned the overt recognition of the role of CT in their pedagogies as well as in general domains of life. Despite such clear acknowledgment, teachers' responses also showed that, apart from the need to systematically incorporate CT in all educational practices in TE programs, the teaching of CT in relation to reading is by no means a fictitious, imagined practice, but existent in different forms.

As the following quotation reveals, Andrea, who, as shown in an earlier comment, is fully aware of the significance of CT to the teaching of reading, elaborates on her response by mentioning that more explicit and systematic reference to CT only happened at a master's level. She stressed that although she does remember learning principles of critical pedagogy in her teacher training course, these pedagogies were never constant, systematic, or sufficient to incorporate them into her own teaching practices. Another misleading or confusing point about CT, as Andrea seems to have learned, is that CT should be applied to texts that have some religious or political ideas. Every text, in a sense, can be looked at critically (Hermas, 2018) because in most texts there could be a tone of hidden power that is embedded. Criticalness means reading enough surrounding a text in a systematic way to be able to make a relatively sound judgment about what to believe, regardless of politics and religion. This was reflected in Andrea's observation:

\section{I actually studied very little about critical thinking, but it did happen in different ways, like trying to find a political or religious ideology in texts, but it didn't happen every time we worked with texts. It was just sometimes, but in my masters' course I really needed more knowledge of principles of critical thinking to understand better the underlying meanings in texts.}

The teacher's recognition of a need for 'more knowledge of principles of critical thinking' at a masters' course reveals not only the apparently inconsistent pedagogical practices used to deal with $\mathrm{CT}$ in reading in undergraduate TE courses, but the seemingly distinct pedagogies and practices used in the treatment of reading in postgraduate courses. Despite this, Andrea does acknowledge the (limited) presence of $\mathrm{CT}$ in different forms, including unpacking texts for political or religious ideologies. Her opinion is shared by another teacher- Fernando- who values the different approaches used by different lecturers when teaching reading, as seen from the quote below.

\section{I always felt disadvantaged when we had classes with certain lecturers because there were texts really interesting that you could discuss in more detail, but the way they [the lecturers] treat them is just like ok, read the text and answer the questions, and}


that's it. But there were other teachers [lecturers] who were more...like on philosophy and they encourage the students to discuss, give opinions, and show a critical position.

Fernando's observation is probably a reflection of how a number of students feel when reading texts are dealt with in simple, traditional, superficial ways that simply reproduce dominant views of thinking and doing without uncovering the hidden ideologies, or messages, that need questioning. However, he recognizes that other lecturers do delve deeper into the reading materials, thus encouraging students' critical stance towards the readings. The main point about Fernando's comment is that many teachers have the propensity to educate their students in the same way they have been trained. This by no means suggests that teachers have completely abandoned a sense of criticality in their pedagogies; rather, it may reflect teachers' lack of awareness of how their own past experiences of teaching and learning are replicated in their current pedagogies. Other students overtly recognized that the way they were taught is a clear reflection of how their own lecturers were taught. Andrea's observation is as follows:

\section{Most of the teachers would agree that we didn't really have critical thinking as a subject, or that we were not really pushed to go deeper into the meanings of texts, but I would say that the professors that don't really push you to find other meanings in the text is because they probably studied pedagogy in Pinochet times when the government wanted everybody to think the same. But even in those days there were many people that resisted the government so I guess critical thinking has always been there but it was useless in education.}

In the quote above, Andrea has a significant point to make. She rightly thinks that $\mathrm{CT}$ can be an individual act and understanding. Not only our culture and the language we speak can influence our perception of CT towards a text, but as Andrea maintains, it could be as well an individual endeavor. An example of this is individual writers in any non-democratic country, which despite their lack of freedom and severe constraints in their society, they become powerful critical readers and writers, although they have been trained in the same education system where there has been little tolerance for $\mathrm{CT}$ by the authorities. It is, however, worthy of mentioning that the numbers of these individuals do not exceed beyond a handful of influential writers. They are the ones who have accepted the consequences of their uncompromising blunt language to authorities.

Two salient elements from the above comments are worth attention. Firstly, in Andrea's comment we can observe that she seems to identify some of the critical problems in current pedagogies for critical reading, thus indicating that much of what educators do in the classroom is influenced by the socio-political events and activities that took place during their own teacher preparation. She highlights in particular the possible influence of the social, cultural and intellectual oppression exercised in Pinochet's military regimen on her lecturer's approach to reading. If this were the case, one could argue that the dominant discourses of power and inequality that dictated education in those days continued to be reproduced in teachers' current pedagogies, thus creating what Rousseau called "a society of slaves, men who had lost their original liberty that was theirs by birthright" (Wain, 2011, p. 1). Secondly, Andrea's last remark suggests that although CT pedagogies have always been present even in times of political oppression, they did not seem to have had much impact on the formation of pedagogies and practices of resistance to ideological and hegemonic forces.

A similar observation is made by the following teacher:
I think that critical thinking is actually present but in different ways, because different people see it different. I remember that when I had applied linguistics in university our professor was very dynamic, active, and critical every time we saw a new theory or a specific reading. She used to ask us how is this theory related to education today, how do you see the theory in the classroom in these days, and that was a very good opportunity to not just learn the theory but think in more critical ways about the theory being useful or applicable to today.

Paula's view of CT is quite interesting. Firstly, the idea that CT is seen differently by different people clearly suggests that Paula seems to understand that different cultures, communities and societies view ways of doing and thinking differently. This would lead us to assume a sociocultural basis of CT, which would, in turn, point to the existence of CT across cultures. As maintained by 
Paton (2015), a CT that is practiced in a certain culture cannot simply be transferred to another culture. For instance, the author asserts that Western forms of CT are not readily teachable to students of Asian background, who usually find western principles of criticality and reasoning difficult to follow. This is not to say that CT does not exist among them, but the way it is perceived is very different from the way it is learned and treated in the west.

The above quotes demonstrate that despite teachers' recognition of the systematic presence of CT pedagogies throughout their teacher training programs, CT is prevalent in a variety of forms, and pedagogically instantiated in different ways by different educators. Some of these instances involved a great impetus for a more dynamic, active and critical way of dealing with reading texts in an attempt to develop students' capacity to see the act of reading not as product but as a complex situated social practice. The teachers' overt recognition that CT does exist in a variety of forms, despite the impact of sociopolitical events on teaching and learning practices, constitutes a platform for discussion, reconsideration and reexamination of how reading texts are dealt with, and how approaches to critical pedagogy may find a more well-delineated route to its implementation.

$R Q$ 2: What are the perceived challenges faced by in-service teachers in implementing and practicing critical pedagogy in their own teaching contexts?

\subsection{Feeling pressured for assessment}

This theme-feeling pressured for assessment-, that is, the perceived challenges faced by in-service teachers in implementing and practicing critical pedagogy in their own teaching contexts indicates teachers' great concerns about curriculum, organizational and pedagogical limitations that polarize any attempt to exercise some form of critical pedagogy approach to the teaching of reading. It became particularly salient in the data that teachers feel unrelenting pressure from managers, principal administrators and, above all, the entire education system to engage in constant, unnecessary testing practices. One teacher- Sandra- commented that:

\section{It's really tiring having to prepare, check, correct and give students so many tests in one semester that I find it very, very difficult to do tasks or activities where students could develop a higher level of critical thinking.}

Driven by systematic approaches to accountability through testing, most governments in Chile have, for over two decades now, supported and encouraged a managerial culture in schools which has embraced large-scale high stakes standardized testing in pursuit of school improvement, and highquality teaching and learning. Although Sandra does not seem to be talking about high stakes tests, her observation voices very clearly what several researchers (e.g., Klenowski \& Wyatt-Smith, 2012) have argued regarding the "increased pressure on schools and teachers to account for teacher and school improvement". The need to engage in activities to develop students' CT skills, as reported by Sandra, is overshadowed by the constant measures of students' learning that have to be prepared, administered and marked.

The heightened pressures to assess students do not only seem to generate physical, emotional and mental tiredness, but create profound feelings of frustrations in teachers as the frequency and length of assessments have a tremendous impact on students' learning and development of English language skills. Fernando expresses great concerns about his students' slow progress in language learning:

\section{All the tests that students have to do is really bad as they don't really have quality time to focus on improving their learning. I think they're all stuck because of the tests. Also, the main problem about the tests is that they generally focus on grammar, reading and vocabulary that they don't really know how to use meaningfully.}

There are two significant points made by Fernando. First, it is the impact of testing on students' learning. Second, it is the content and nature of language tests. Regarding the former, effective and successful instructional pedagogies appear to be hampered by time-consuming testing practices which have, perhaps, unintended consequences for students' learning. The latter is clearly pointing to a lack of congruence between the language content taught to and learned by students and the real communicative needs of learners. As observed by Fernando, the lack of meaningfulness in what is learned (e.g., reading and vocabulary) and how it is learned can jeopardize not only teachers' 
purposeful attempts to present the content in more meaningful ways but also the efforts and motivations of those students in pursuit of real instances for learning and communication.

Fernando's remarks are reiterated by Paula who stresses the incongruities between the real needs of students and the actual teaching practices:

\begin{abstract}
Well, the students have to be able to communicate effectively in the real world and this is what they need. And, it's important to develop the critical thinking skills they need to read different kinds of texts and to be able to write using critical ideas, but the system, the number of tests and of students in class, the lack of resources don't allow for that.
\end{abstract}

Paula's reflection is critical of the separation between what she thinks the students really need and the limitations that seem to prevent the realization of meaningful teaching and learning practices. She is cognizant of the role of CT in helping students deal with a variety of texts in reading. However, the barriers pertaining to the overall educational system which fosters unnecessary testing practices are certainly limiting the capacities of both teachers and students to unravel the meanings, messages and ideologies embedded in the texts that English language learners have to read. This is further clarified in Paula's following observation:

\title{
... because of all these problems and limitations, we don't really have the time to teach students how to assess and evaluate the assumptions in texts. Students read because it's a skill they have to develop, but that's it.
}

This comment is ratifying the relegation of CT skills as a result of the barriers mentioned by Paula in her previous comment. Apart from the pressures relating to testing and assessment, the lack of time is an essential commodity, which, in this case, is not at the service of developing critical reading skills required in today's world. On the contrary, it can be argued that whatever amount of time is allocated to reading privileges the content that must be covered, the curriculum objectives that must be achieved, and perhaps the accountability standards to which the teacher has to respond, all of which appear to contribute to dominant reading pedagogical practices stagnating into a set of less meaningful, and highly routinized procedures.

The representative samples of teachers' responses in this section provide interesting insights into the complexities surrounding the teaching of CT skills. The increasingly unnecessary testing practices, as indicated by the teachers, aggravates teachers' problems in their attempts to incorporate more dialogic approaches to reading through which students can be assisted to assess, evaluate and unpack texts in a manner that they gain a more critical perspective on what they are reading. Despite the teachers' overt recognition of the significance of developing students' CT skills, the pedagogical challenges, which appear to be firmly rooted in a dominant culture of compliance and managerial approaches to the teaching of reading, seem to be the major hurdles in the process of adopting a critical pedagogy approach to reading in Chile.

\section{Conclusion}

This study reported on research into the challenges of implementing a critical pedagogy approach to the teaching of reading in ELT contexts in Chile. The paper sought to uncover and examine inservice ELT teachers' perceptions and understandings of CT as well as the perceived challenges associated with the implementation of a critical pedagogy approach to the teaching of reading. Regarding the pedagogical challenges encountered by teachers, our interview data revealed that the managerial culture that dominates the Chilean education system, places teachers under considerable pressure to high-stakes testing practices, which are generally aimed at meeting public accountability and maintaining public confidence in the standards, quality and effectiveness of schooling (Lewis \& Young, 2013). This does not only obscure the possibility to approach English language learning, and particularly reading, through critical lenses, but constrain, and potentially deskill, teachers who, despite their profound depth of professional knowledge and desire to treat the teaching of reading differently, grapple with the pressing demands of an educational, organizational structure that favors a culture of reproduction rather than 'creative production' (Crookes \& Lehner, 1998).

A critical reading of academic texts arises from the ideological perspectives and social and discourse practices that are embedded in the public discourse and the acquisition of knowledge and 
the formation of power in a society (Crookes \& Lehner, 1998). Relevant curriculum and pedagogic planning, proper assessment construction and assessment tools, appropriate methodological nuances in teaching relevant to the discourse in Chile are required to advance the argument of CT and critical reading among curriculum planners, educators, students and the public. It is argued that academic texts are embedded in socio-cultural public discourses, and that the analysis of texts and the implementation of critical reading in classroom should be constructed in a way that students become strongly involved in how culture, politics, and ideology work together to disempower certain groups and empower other groups.

\section{REFERENCES}

Aghaei, K., Koo, Y. L., Noor, N. M., \& Rajabi, M. (2014). From theory to practice: theater reading (TR) as a critical and transformative literacy practice in an educational development course. Procedia-Social and Behavioral Sciences, 118, 37-41. https://doi.org/10.1016/j.sbspro.2014.02.005

Ahmadi, A., \& Maftoon, P. (2015). Rethinking the language learner in the post-method era the question of identity. Procedia-Social and Behavioral Sciences, 192, 267-274. https://doi.org/10.1016/j.sbspro.2015.06.039

Atkinson, D. (1997). A critical approach to critical thinking in TESOL. TESOL Quarterly, 31(1), 71-94. https://doi.org/10.2307/3587975

Banegas, D., \& Villacañas de Castro, L. (2016). Criticality. ELT Journal, 70(4), 455-457. https://doi.org/10.1093/elt/ccw048

Barkhuizen, G. (2016). A short story approach to analyzing teacher (imagined) identities over time. TESOL Quarterly, 50(3), 655-683. https://doi.org/10.1002/tesq.311

Barnett, W. S. (2011). Effectiveness of early educational intervention. Science, 333(6045), 975-978. https://doi.org/10.1126/science.1204534

Bellei, C., \& Munoz, G. (2021). Models of regulation, education policies, and changes in the education system: a long-term analysis of the Chilean case. Journal of Educational Change, 1-28. https://doi.org/10.1007/s10833-021-09435-1

Beltrán, A., \& Preller, J. (2003). Impacto de la dictadura militar (1973-1990) en la nueva narrativa Chilena. Análisis de casos. (Tesis para optar al título de Periodista), Universidad Austral de Chile, Valdivia, Chile. Retrieved from http://cybertesis.uach.cl/tesis/uach/2003/ffb548i/doc/ffb548i.pdf

Benesch, S. (1993). Critical thinking: A learning process for democracy. TESOL Quarterly, 27(3), 545-548. https://doi.org/10.2307/3587485

Brown, J., Charles, C., Doecke, B., \& Kostogriz, A. (2004). Heteroglossia: a space for developing critical language awareness? Paper presented at the AARE 2004: Doing the public good: positioning educational research.

Creswell, J. W., \& Poth, C. N. (2016). Qualitative inquiry and research design: Choosing among five approaches. California: Sage Publishing.

Crookes, G., \& Lehner, A. (1998). Aspects of process in an ESL critical pedagogy teacher education course. TESOL Quarterly, 32(2), 319-328. https://doi.org/10.2307/3587586

Davies, M., \& Barnett, R. (Eds.). (2015). The Palgrave handbook of critical thinking in higher education. New York: Palgrave Macmillan. https://doi.org/10.1057/9781137378057

Davis, M. (2011). Introduction to the special issue on critical thinking in higher education. Higher Education Research and Development, 30(3), 255-260. https://doi.org/10.1080/07294360.2011.562145

Dobinson, T. (2014). Occupying the 'third space': perspectives and experiences of Asian English language teachers. In K. Dunworth \& G. Zhang (Eds.), Critical perspectives on language education: Australian and the Asia Pacific (pp. 9-28). New York: Springer. https://doi.org/10.1007/978-3-319-06185-6_2

Floyd, C. (2011). Critical thinking in a second language. Higher Education Research and Development, 30(3), 289-302. https://doi.org/10.1080/07294360.2010.501076 
Goodman, S., \& Cocca, C. (2014). "Spaces of action": Teaching critical literacy for community empowerment in the age of neoliberalism. English Teaching: Practice and Critique, 13, 210-226.

Hermas, A. (2018). Discourse-linking in advanced L3 English: Testing the interface hypothesis. Lingua, 212, 20-29. https://doi.org/10.1016/j.lingua.2018.05.004

Huber, C., \& Kuncel, N. (2016). Does college teacher critical thinking? A meta-analysis. Review of Educational Research, 86(2), 431-468. https://doi.org/10.3102/0034654315605917

Inzunza, J., Assaél, J., \& Scherping, V. (2011). Formación docente inicial y en servicio en Chile. Revista Mexicana de Investigación Educativa, 16(48), 267-292.

Janks, H. (2014). Critical literacy's ongoing importance for education. Journal of Adolescent and Adult Literacy, 57(5), 349-356. https://doi.org/10.1002/jaal.260

Junejo, M. R., Sarwar, S. \& Ahmed, R. R. (2017). Impact of in-service training on performance of teachers: A case of STEVTA Karachi Region. International Journal of Experiential Learning \& Case Studies, 2(2), $50-60$.

Klenowski, V., \& Wyatt-Smith, C. (2012). The impact of high stakes testing: the Australian story. Assessment in Education: Principles, Policy and Practice, 19(1), 65-79. https://doi.org/10.1080/0969594X.2011.592972

Lau, S. M. C. (2013). A study of critical literacy work with beginning English language learners: An integrated approach. Critical Inquiry in Language Studies, 10(1), 1 30. https://doi.org/10.1080/15427587.2013.753841

Lewis, W., \& Young, T. (2013). The politics of accountability: Teacher education policy. Educational Policy, 27(2), 190-216. https://doi.org/10.1177/0895904812472725

Lin, A., \& Luk, J. (2015). Voices without words: Doing critical literate talk in English as a second language. TESOL Quarterly, 49(1), 67-91. https://doi.org/10.1002/tesq.161

Manarin, K., Carey, M., Rathburn, M., \& Ryland, G. (2015). Critical reading in higher education: academic goals and social engagement. Bloomington and Indianapolis: Indiana University Press.

Marzban, A., \& Barati, Z. (2016). On the relationship between critical thinking ability, language learning strategies, and reading comprehension of male and female intermediate EFL university students. Theory and Practice in Language Studies, 6(6), 1241-1247. https://doi.org/10.17507/tpls.0606.14

Moghadam, Z. B., Narafshan, M. H., \& Tajadini, M. (2021). Development of a critical self in the language reading classroom: An examination of learners' L2 self. Thinking Skills and Creativity, 42, 100944. https://doi.org/10.1016/j.tsc.2021.100944

Moore, T. (2011). Critical thinking and disciplinary thinking: a continuing debate. Higher Education Research and Development, 30(3), 261-274. https://doi.org/10.1080/07294360.2010.501328

Mora, D. (2013). Pensamiento crítico en el currículum oficial y en los textos escolares. Propuesta didáctica: "La Revolución Industrial". (Magister en Enseñanza en las Ciencias Sociales), Universidad del Bio Bio, Chillán. Retrieved from http://repobib.ubiobio.cl/jspui/bitstream/123456789/366/1/Mora_Godoy_Danilo.pdf

Mora, R. A. (2014). Critical literacy as policy and advocacy. Journal of Adolescent and Adult Literacy, 58(1), 16- 18. https://doi.org/10.1002/jaal.329

Nuñez, I. (1984). Las transformaciones educacionales bajo el régimen milital (Vol. 1). Santiago de Chile: PIIE.

Orlowski, P. (2011). Teaching about hegemony: Race, class and democracy in the 21st century (Vol. 17). Springer Science \& Business Media.

Paton, M. J. (2015). The geography of styles of reasoning: East and West, North and South. Philosophy East and West, 65(1), 178-195. https://doi.org/10.1353/pew.2015.0022

Rogers, R. (2014). Coaching literacy teachers as they design critical literacy practices. Reading and Writing Quarterly, 30(3), 241-261. https://doi.org/10.1080/10573569.2014.909260 
Romero, E. D., \& Bobkina, J. (2021). Exploring critical and visual literacy needs in digital learning environments: The use of memes in the EFL/ESL university classroom. Thinking Skills and Creativity, 40, 100783. https://doi.org/10.1016/j.tsc.2020.100783

Shahri, M. N. N. (2018). The development of teacher identity, emotions and practice: Before and after graduation from an MA TESOL program. System, 78, 91-103. https://doi.org/10.1016/j.system.2018.08.003

Shokouhi, H., \& Latifi, M. (2019). Empowerment and knowledge transformation through critical reading and thinking: A case study of Iranian university students. In Chowdhury, R. (ed), Transformation and empowerment through education: Reconstructing our relationship with education, pp. 58-72. Routledge. https://doi.org/10.4324/9780429431050-4

Smith, T., Rama, P., \& Helms, J. (2018). Teaching critical thinking in a GE class: A flipped model. Thinking Skills and Creativity, 28, 73-83. https://doi.org/10.1016/j.tsc.2018.02.010

Tang, L. (2016). Exploration on cultivation of critical thinking in college intensive reading course. English Language Teaching Journal, 9(3), 18-23. https://doi.org/10.5539/elt.v9n3p18

Toy, B. Y. \& Ok, A. (2012). Incorporating critical thinking in the pedagogical content of a teacher education programme: Does it make a difference? European Journal of Teacher Education, 35(1), 39-56. https://doi.org/10.1080/02619768.2011.634902

Wain, K. (2011). On Rousseau: An introduction to his radical thinking on education and politics. Rotterdam: Sense Publishers. https://doi.org/10.1007/978-94-6091-385-3

Wallace, C. (2003). Critical reading in language education. New York: Palgrave Macmillan. https://doi.org/10.1057/9780230514447

Wallace, E., \& Jefferson, R. (2015). Developing critical thinking: Assessing the effectiveness of workbook exercises Journal of College Teaching and Learning, 12(2), 101-108. https://doi.org/10.19030/tlc.v12i2.9187

Wass, R., Harland, T., \& Mercer, A. (2011). Scaffolding critical thinking in the zone of proximal development. Higher Education Research and Development, 30(3), 317-328. https://doi.org/10.1080/07294360.2010.489237

Welch, K., Hieb, J., \& Graham, J. (2015). A systematic approach to teaching critical thinking skills to electrical and computer engineering undergraduates. American Journal of Engineering Education, 6(2), 113-123. https://doi.org/10.19030/ajee.v6i2.9506

Yousefi, S., \& Mohammadi, M. (2016). Critical thinking and reading comprehension among postgraduate students: The case of gender and language proficiency level. Journal of Language Teaching and Research, 7(4), 802-807. https://doi.org/10.17507/j1tr.0704.23 